\title{
Adverse Childhood Experiences, Psychological Distress, and Fathering Behaviors
}

\author{
Kevin Shafer \\ Brigham Young University, kshafer@byu.edu \\ Scott D. Easton \\ Boston College
}

Follow this and additional works at: https://scholarsarchive.byu.edu/facpub

Part of the Family, Life Course, and Society Commons

\section{Original Publication Citation}

Shafer, K. and Easton, S.D., "Adverse Childhood Experiences, Psychological Distress, and Fathering Behaviors," Journal of Marriage and Family (2021).

\section{BYU ScholarsArchive Citation}

Shafer, Kevin and Easton, Scott D., "Adverse Childhood Experiences, Psychological Distress, and Fathering Behaviors" (2021). Faculty Publications. 4915.

https://scholarsarchive.byu.edu/facpub/4915

This Peer-Reviewed Article is brought to you for free and open access by BYU ScholarsArchive. It has been accepted for inclusion in Faculty Publications by an authorized administrator of BYU ScholarsArchive. For more information, please contact ellen_amatangelo@byu.edu. 
KeVIn SHAFER Brigham Young University

Scott D. Easton Boston College*

\section{Adverse Childhood Experiences, Psychological Distress, and Fathering Behaviors}

Objective: This study examines the relationship between adverse childhood experiences (ACEs), internalized and externalized psychological distress, and six measures of parenting behavior among fathers in the United States.

Background: Prior research on ACEs and parenting has focused almost exclusively on mothers, specific types of childhood adversity, and the intergenerational transmission of abuse, neglect, and other traumatic experiences. This study extends the literature by considering ACEs in fathers, using a multidimensional measure of ACEs, and multiple measures of positive and negative fathering behavior.

Method: Using the ecological model of father involvement, this study is based on a national sample of more than 2,000 fathers with children between 2 and 18 years old in the United States. Seemingly unrelated regression models were used to analyze the relationship between ACEs and each fathering behavior, with two measures of psychological distress included as mediators of this relationship.

Results: ACEs are significantly associated with both internalized and externalized psychological distress. Experiencing multiple ACEs was

Department of Sociology, Brigham Young University, 2019 JFSB, Provo, UT 84602 (kevin_shafer@byu.edu).

${ }^{*}$ School of Social Work, Boston College, 207 McGuinn Hall, Chestnut Hill, MA 02567.

Key Words: child abuse, fatherhood, fathers, mental health, parent involvement. negatively associated with paternal warmth, engagement, caregiving, and father-child relationship quality. Multiple ACEs were also positively associated with the use of harsh discipline. High ACE scores were mediated by internalized distress for five fathering behaviors and by externalized distress for warmth and harsh discipline.

Conclusion: This study highlights the importance of ACEs and psychological distress for fathering. These results have implications for future research and public health approaches to childhood trauma.

\section{BACKGROUND}

Abuse, neglect, family dysfunction, and other traumatic childhood events have extensive short- and long-term effects (Anda et al., 2010). Increased adverse childhood experience (ACE) scores are associated with poorer physical health, more psychological distress, significant risk for social isolation, low educational attainment, difficulty in maintaining stable employment, and many other problems (Umberson et al., 2008). Childhood adversity is also associated with parenting and, in turn, a myriad of child outcomes, including physical, psychological, social, and developmental well-being. Two distinct strands of research focus on this relationship. One group of studies considers the intergenerational transmission of childhood adversity by linking parental experiences of abuse and neglect in childhood to the likelihood of acting abusively or neglectfully as a parent 
(Widom et al., 2015). The second group considers that parents with traumatic backgrounds may break intergenerational cycles of abuse and neglect, but still have lower engagement and involvement than mothers and fathers with low or no childhood adversity. As a result, these studies consider parenting quality through a range of positive parenting outcomes like warmth, providing emotional support, physical caregiving, and parent-child relationship quality (Fuchs et al., 2015).

The literature on ACEs and parenting is limited in two important ways, however (Brown et al., 2020; DiLillo et al., 2000; Fuchs et al., 2015; Schuetze \& Eiden, 2005; Thornberry et al., 2012; Widom et al., 2015). First, fathers are often ignored because of data limitations and assumptions about maternal parenting primacy. Yet, paternal roles and expectations for fathers have shifted in recent decades, meaning that fathers participate more in child care and other aspects of parenting, resulting in a greater impact on the health, well-being, and development of children (Cabrera et al., 2018; Fagan et al., 2014; Lamb, 2010; Palkovitz, 2019; Palkovitz et al., 2014; Schoppe-Sullivan \& Fagan, 2020). Thus, the lack of empirical work on the relationship between childhood adversity and fathering behavior may limit our understanding of how fathers influence children physically, psychologically, socially, and developmentally. Moreover, expanding research on ACEs and parenting to include fathers acknowledges that men experience childhood adversity at relatively high rates. National estimates of physical and sexual abuse in the United States, for example, suggest that 1 in 7 men are victimized as children (Centers for Disease Control and Prevention, 2010; Easton, 2014). Second, few studies on ACEs and subsequent parenting account for comorbidity among adversities, nor the potential compounding effects of experiencing multiple ACEs (Widom et al., 2015). Although studies focused on how childhood sexual abuse or neglect make significant contributions, the broader literature on ACEs emphasizes the relationship between accumulated childhood adversity and a diverse range of adult outcomes (Anda et al., 2010; Umberson et al., 2014; Williams \& Finch, 2019). Addressing this gap in the literature is valuable for several reasons. A focus on ACEs contributes to the fathering literature by providing additional insights into how family-of-origin (FOO) and child socialization influence how men parent their children. Prior studies focused on the early roots of father involvement often contemplate how cumulative processes of disadvantage may influence parenting behavior (Roy, 2014), providing important insights into men's parenting behavior-but rarely consider how childhood trauma and adversity are associated with economic and social marginalization (Umberson et al., 2014). Moreover, by comparing the results obtained in studies on maternal ACEs to patterns among fathers, our study can help elucidate how the relationship between parenting, childhood adversity, and mental health dovetails with gendered norms and expectations about the parental role.

Life course research demonstrates that ACEs are chronic stressors that are robustly and negatively associated with psychological well-being (Chapman et al., 2004). Thus, while ACEs may have a direct relationship with fathering, its relationship may also be mediated by psychological distress - a more proximate stressor associated with decreased positive and increased negative parenting behavior (Shafer et al., 2019; Wilson \& Durbin, 2010). Notably, psychological distress may be manifested in gendered ways. Men are more likely to externalize their symptoms, including rage, yelling, and problematic substance use than women and are less likely to experience internalized distress that is more frequently associated with clinical conceptualizations of depression and anxiety (Addis, 2008; Rosenfield \& Mouzon, 2013). Using a national sample from the United States, we address these issues by (a) considering the relationship between ACEs and six measures of fathering consistent with contemporary and sometimes contradictory expectations of fathers (Petts et al., 2018): warmth, emotional support, positive control, harsh discipline, caregiving, and father-child relationship quality and (b) measuring the potential mediating influence of psychological distress on the relationship between ACEs and fathering behavior using measures of both internalized and externalized distress - an approach consistent with gendered response models.

\section{Childhood Adversity and Parenting}

Ecological models (Cabrera et al., 2014) theorize that personal histories, including childhood experiences, cultural factors, and current 
context, are significant predictors of how men both define and engage with the paternal role (Adamsons \& Pasley, 2016; Edin \& Nelson, 2013; Hofferth \& Goldscheider, 2010; Petts et al., 2018; Shafer et al., 2017; Young et al., 2014). Moreover, an ecological framework acknowledges that fathering takes place within and is influenced by a network of interpersonal relationships and interactions. Thus, this framework is useful to understand barriers and facilitators of fathering at multiple levels and across the life course. Importantly, Cabrera et al.'s (2014) expanded ecological model of fathering is heuristic, allowing for a focus on particular characteristics, while simultaneously acknowledging various contextual factors associated with fathering and subsequent child outcomes. As a result, the ecological framework is uniquely suited to consider the relationship between childhood adversity and fathering behavior, given the model's explicit inclusion of personal history as a critical aspect of understanding how men parent.

We conceptualize ACEs as a set of interrelated chronically stressful events with physiological, psychological, social, and behavioral consequences that last into adulthood, including the potential to influence how fathers act toward and interact with their children (Williams \& Finch, 2019). In order to capture accumulated adversity, we use the Centers for Disease Control and Prevention's (2019) standardized measure of ACEs to consider how events and experiences in one's FOO and childhood shape how men parent their children. Consistent with this conceptual definition, we operationalize childhood adversity and trauma with a cumulative measure for several reasons. First, there is significant correlation between various ACEs, suggesting that there can be broad exposure to many negative experiences in FOOs. For example, Felitti and colleagues (1998) found that 52\% of individuals exposed to psychological abuse in childhood reported experiencing physical abuse, $47 \%$ report being sexually abused, and $51 \%$ report an adult in their household had a substance abuse problem. Second, ACE dosage is a strong predictor for many physical, psychological, and behavioral outcomes (Anda et al., 2010). In many cases, individuals with ACE scores of 3 or higher tend to do worse than individuals with low or no childhood adversities. These patterns are consistent with some formulations of the stress model, which posit that accumulated stressors are psychologically, physically, and socially overwhelming - outstripping the social and personal resources that can mitigate the negative effects associated with exposure to a limited number of stressors (Turner, 2013). Third, childhood adversities have well-documented effects on how families operate, couples work together, and individuals parent (Kwon et al., 2003; Ponnet, 2014). Studies focused on the direct relationship between ACEs and parenting behavior, focused almost exclusively on mothers, provide some evidence for the intergenerational transmission of abuse, neglect, and maltreatment. Relatedly, maternal ACEs are also negatively associated with measures of parenting quality, such as warmth, physical caregiving, and emotional support (DiLillo et al., 2000; Schuetze \& Eiden, 2005; Thornberry et al., 2012).

Although previous work on maternal ACEs helps illuminate our study, fathering exists within a web of cultural, individual, and contextual influences that is distinct from mothers (Holmes et al., 2010), suggesting that ACEs may have a unique, direct, and negative impact on how men parent (Brown et al., 2018; Shafer, Petts, \& Scheibling, 2020). Culturally, there are contradictory expectations about the roles and responsibilities associated with fatherhood. Traditionally, fathers have taken on authoritative roles, like breadwinning and child discipline (Doucet, 2014). Such behaviors are strongly institutionalized in both cultural norms and social structures, such as the workplace (Petts et al., 2018). At the same time, paternal roles have evolved over time and men are now increasingly engaged in parenting behaviors such as warmth, emotional support, and providing for a child's physical needs. These behaviors, however, have been traditionally "female coded." These roles and responsibilities are far less institutionalized among fathers than mothers, meaning that individual and contextual factors are more strongly linked to men's instrumental and expressive parenting than women's (Brown et al., 2018; Doucet, 2006; Guzzo, 2011; Scheibling, 2018).

Important for understanding the effect of ACEs on fathering, many men interact with their children in ways that reflect how they were parented when they were a child (Roy, 2006; Roy \& Smith, 2012). Qualitative studies, commonly focused on fathers from low-income and BIPOC (Black, Indigenous, and People of 
Color) populations, find variability in how FOOs influence fathers. One group of studies notes that childhood experiences, both positive and negative, are frequently reflected in one's own parenting (Bouchard, 2012; Brown et al., 2018; Guzzo, 2011). In some cases, fathers rely more heavily on experiences with their mothers, kin, or other members of their social networks than their fathers to help socialize them to parental roles and responsibilities (Roy, 2014; Roy et al., 2008). A second set of findings indicate that one's relationship with their own father is significantly associated with how strongly they identify as a father, but not with their engagement in instrumental or expressive parenting (Coates \& Phares, 2014; Shears et al., 2006). Meanwhile, a third group of studies show that some men compensate for their own father's poor or nonexistent parenting by forming their own ideas about paternal involvement (Bar-On \& Scharf, 2016; Daly, 1996).

Although insightful, this literature is limited in two significant ways. First, most studies use small, homogeneous community samples drawn from populations that are at-risk for high ACE scores and social instability. It is unclear if such a relationship would hold in a diverse, national sample. Second, negative or traumatic interactions in one's FOO are rarely considered in the literature, with most studies instead focused on father-child relationship quality. A notable exception is a study of Black fathers by Brown et al. (2018), who found a negative correlation between ACEs, father involvement, and relationship quality with one's own father. Overall, however, evidence around socialization, ACEs, and fathering is decidedly mixed. If patterns are consistent with parental modeling, ACEs could be negatively associated with numerous dimensions of fathering. In contrast, patterns of compensation would lead fathers to reshape the paternal role to engage more positively with children, leading to a null or positive relationship between ACEs and fathering.

Working in conjunction with interpersonal, socializing experiences in childhood, social resources also play an important role in shaping father's engagement in instrumental and expressive parenting in the absence of institutionalized norms about contemporary fathering (Palkovitz \& Hull, 2018). Although Palkovitz and Hull (2018) outline significant lists of potential fathering resources, ACEs are generally associated with men's ability to invest in and employ personal (i.e., income, health status), interpersonal (i.e., coparenting, social support), and contextual (i.e., attitudes about parenting, employment) resources in their parenting. For example, elevated ACE scores increase risk for economic distress, unemployment, lack of educational opportunities, and poor health (Lehman et al., 2009; Nurius et al., 2015; Shin et al., 2013). Other important resources for fathers, like access to social support, provide advice, education, and informal help that can be critical to engaged parenting by men (Fagan \& Palkovitz, 2011; Uchino et al., 2018). Overall, social resources are strongly associated with men's contributions in families, including positive fathering directed toward positive developmental, psychological, and social outcomes in children (Palkovitz, 2019; Pleck, 2010). Indeed, underresourced fathers often feel that they lack the skills necessary to be highly engaged in parenting and significantly stressed when they do become involved (Palkovitz \& Hull, 2018) and in some cases focus their efforts on economic provision because they see themselves as unprepared or inadequate caregivers (Schoppe-Sullivan \& Fagan, 2020).

\section{ACEs, Psychological Distress, and Fathering Behavior}

In addition to the hypothesized direct pathway between ACEs and fathering, the relationship may be mediated by psychological distress. Many studies have demonstrated a connection between childhood adversity and psychological distress in adults. ACE scores are positively and chronically associated with interpersonal conflict, elevated depressive symptoms, anxiety, substance misuse, and other measures of mental health in both men and women. The possibility that ACEs' association with fathering is mediated through psychological distress is meaningful given the latter's relationship with fathering behaviors. Fathers' distress is associated with decreased instrumental parenting, expressive parenting, and coparenting (Bronte-Tinkew et al., 2007; Cavanaugh et al., 2015; Leach et al., 2014; Shafer et al., 2017, 2019; Umberson \& Williams, 1993; Wilson \& Durbin, 2010). Depressive symptoms are also linked to the use of physically and emotionally harsh disciplinary techniques that are associated with negative short- and long-term outcomes in children (Altschul et al., 2016; 
Lee et al., 2015; Liu \& Wang, 2015). As a result, paternal distress is associated with internalized and externalized behavioral problems, poorer physical health, mental health issues, and decreased academic achievement in children (Gladstone et al., 2015; Padilla-Walker et al., 2016; Wilson \& Durbin, 2010). Notably, the role of paternal ACEs as a distal factor in the relationship between distress, fathering, and child outcomes remains unexplored.

Although prior research has shown that psychological distress significantly mediates the relationship between ACEs and mothering, there is good reason to suspect a different relationship among fathers. Psychological distress is typically operationalized with measures of internalized symptoms, such as anxiety, depressive mood, or hopelessness (Young et al., 2014). Gendered response models suggest that such constructs may underestimate men's distress levels by excluding externalized psychological issues. Indeed, men are more likely to express distress in such ways (Addis, 2008; Rosenfield \& Mouzon, 2013). In the United States and many other Western countries, women are diagnosed with major depression at about twice the rate men are (Rosenfield \& Mouzon, 2013), while men are far more likely to problematically use alcohol, illegal narcotics, and prescription drugs (Becker et al., 2016). These trends suggest that a broader conceptualization of psychological distress is necessary, particularly in studies with or including men. Indeed, the small literature on internalized and externalized distress in men and fathers suggests that studies that consider both provide a more complete picture of men's mental health. Comparisons of maternal and paternal psychological distress on children find stronger direct effects for fathers-a relationship associated with externalizing symptoms more commonly displayed in men (Shafer et al., 2017). Studies that find gender differences in the relationship between psychological distress and specific parenting behaviors provide greater insight. For example, distressed mothers tend to decrease their warmth and emotional support, while distressed fathers are often openly hostile (Hummel et al., 2016). Relatedly, research on different forms of distress in American fathers finds that internalized distress was more strongly associated with reductions in emotional and instrumental parenting, while externalized distress had more robust effects on harsh disciplinary techniques (Shafer et al., 2019).
ACEs' association with internalized distress is well established in the literature. Prior work tends to use clinical criteria for depression, anxiety, and other mental health disorders frequently operationalized by measures of internalized distress (Cheong et al., 2017). Less is known about the relationship between ACEs and externalized distress, although several studies have linked childhood adversity to various aspects of it, including alcohol abuse (Crouch et al., 2018), illicit drug use (Dube et al., 2003), and aggression (Jones et al., 2018). Thus, we expect that ACEs are positively associated with internalized and externalized psychological distress in fathers and that both measures of distress will mediate the relationship between ACEs and fathering behavior. Importantly, however, we expect differences across fathering measures. Prior research indicates that internalized distress will have more significant effects on instrumental behaviors, while externalized distress will be more strongly associated with negative outcomes like harsh discipline and expressive behaviors like warmth (Shafer et al., 2019).

Gendered response models argue that adherence to masculine norms is one reason why there is variability in men's responses to psychological distress (Addis, 2008). Traditional norms, like strict avoidance of behaviors that are perceived as feminine and emotional stoicism, influence how men exhibit distress. More specifically, traditional norm adherence is positively associated with externalized distress, but negatively associated with internalized symptoms in both general samples of men (Call \& Shafer, 2018; O’Neil \& Luján, 2010) and fathers (Shafer et al., 2019). Other work finds that masculinity can amplify the negative effects of traumatic childhood experiences, like sexual abuse, on mental health outcomes (Easton, 2014). The endorsement of masculine norms has notable, negative effects on positive fathering behavior, as well (Petts et al., 2018; Shafer et al., 2020), suggesting that gendered expectations about the paternal role may inform how ACEs and psychological distress influence fathering (Pleck, 1995; Pleck, 2010). Some research suggests that childhood adversity and poor mental health are more negatively associated with parenting behaviors less consistent with gendered expectations. Among mothers, for example, childhood adversity has small to no effects on caregiving and instrumental parenting behaviors most strongly associated 
with culturally-defined maternal responsibilities (Khan \& Renk, 2019; Kolomeyer et al., 2016). Relatedly, some research shows that depressive symptoms have little to no relationship with behaviors commonly undertaken by fathers, like monitoring and discipline (Salari et al., 2014; Shafer et al., 2017; Shafer \& Renick, 2020). Thus, there is good reason to expect that ACEs and psychological distress will be negatively associated with expressive fathering behaviors and those instrumental parenting behaviors, like caregiving, that tend to be considered primarily maternal responsibilities. Consistent with these possibilities, we consider multiple dimensions of fathering in our analyses.

\section{Methods}

\section{Data}

We use the Survey of Contemporary Fatherhood (SCF), a US-based national sample of 2,297 biological-, adoptive-, step-, and social fathers collected in 2015-2016. SCF was collected with a focus on father involvement, mental health, and other factors associated with positive paternal engagement. Eligible fathers had to be at least 18 years old, English proficient, have internet or smartphone capability, and identify as a residential or nonresidential biological father, residential or nonresidential adoptive father, residential stepfather married to the child's biological or adoptive parent, residential social father (defined as living with a nonbiological, nonadopted child, but not married to the mother of the child), or residential, related father figure (defined as being related to the child by blood, marriage, or adoption) with at least one child 18 or younger. Following commonly deployed methodologies in the father involvement literature (e.g., Dyer et al., 2018), questions were asked about a focal child, defined as the youngest eligible child between the ages of 2 and 17 years.

SCF is a quota sample used to capture various paternal roles while still producing results comparable to those found in random samples (Weinberg et al., 2014). Potential respondents were randomly selected, based on their sociodemographic profile, from the Qualtrics opt-in panels (in 2015, the available number of panelists, who are recruited via online and offline advertising, was over 15 million individuals in the United States). In order to ensure data accuracy, panelists are asked to verify their identity periodically, may only complete a limited number of surveys in a calendar year, have their responses monitored to ensure consistency, and must update their sociodemographic profile regularly. Panelists who are invited and decide to take the survey are taken to a pre-screening site where sociodemographic information is used to determine eligibility. Eligible respondents had to answer at least $80 \%$ of the survey questions (including answers indicating nonapplicability or refusal to answer) for their data to be considered complete and receive prorated compensation at national living wage standards (MIT Living Wage Calculator, 2020).

Using best practices for online data collection and quota sampling, multiple data quality check strategies were used, including attention filters, identification of careless responses, multiple submission prevention, and time minimums (Tourangeau et al., 2013). 3.8\% of responses were eliminated through these data quality and accuracy checks (Smith et al., 2016; Terhanian et al., 2016). Prior work indicates that online, opt-in panels accurately reflect the population with regular and consistent access to the internet (Tourangeau et al., 2013). Recent estimates from the American Community Survey indicate that nearly $90 \%$ of Americans have regular internet access-although important racial/ethnic, socioeconomic, and spatial disparities persist (Pew Research Center, 2016). Moreover, SCF respondents are sociodemographically comparable to randomized data sets focused on fathering, such as the Survey of American Parents (see Shafer et al., 2019 for more information on SCF's comparability and variability by sampling frame in data sets). Although we caution readers on the representativeness of this sample (Yang \& Banamah, 2014), these data are valuable because it includes robust measures of childhood trauma, distress, and fathering behavior not found in other surveys.

SCF includes measures of fathering behavior that reflect differences in parenting across child age. Developmentally appropriate measures for each domain of fathering behavior were provided for fathers with children aged 2-8 $(n=1,105)$ and children 9-17 $(n=967)$. As we note later, we combine measures, where appropriate, to conduct analyses across fathers, regardless of child age. Supplementary analyses noted that ACEs were not significantly associated with the fathering behaviors of nonresidential fathers. Consistent with other 
studies focused on issues of mental health and fathering (Bronte-Tinkew et al., 2007; Shafer et al., 2017), which consider exposure to be a significant factor in understanding the influence of poor paternal mental health on children, we removed 153 nonresidential fathers from the sample, leaving a final analytic sample of 2,072.

\section{Measures}

Fathering Behaviors. We use six measures of fathering behavior, all of which are associated with positive child development and the emotional, social, and physical well-being of children (Pleck, 2010; Schoppe-Sullivan \& Fagan, 2020; Volling \& Cabrera, 2019). Our conceptualization of fathering behavior is built on Pleck's (2010) multidimensional model of fathering, capturing both instrumental and expressive behaviors (Finley \& Schwartz, 2004). Measures of fathering behavior were derived from secondary data sets commonly used in fathering research, including the Survey of Early Child Care and Youth Development (SECCYD), the Early Childhood Longitudinal Survey-Birth Cohort (ECLS-B), and the National Survey of Family Growth (NSFG). Although our measurement of each construct differs by child age, we standardized each measure to be included in a single analysis. In doing so, each measure is a $z$-score indicating the standard deviation $(S D)$ difference between a respondent's score on a scale and the age group mean. For four of the six measures, we then combined scores into a single outcome variable. Two outcomes were age-specific and did not include analogous measures in both age groups. Supplementary age-group specific analyses yielded substantively similar to those presented here.

Warmth was measured for children of all ages. Eight items included in the ECLS-B were used for fathers of young children $(\alpha=0.87)$. These items asked respondents about how they physically and verbally express love and affection to their children. Fathers indicated if each behavior was reflective of their parenting on a 0 (not at all like me) to 4 (exactly like me) scale, with higher scores indicating warmer parenting. For fathers of older children, warmth was measured with nine items drawn from the SECCYD data ( $\alpha=0.91)$. Items were scored on a 0 (never) to 3 (always) scale and captured similar behaviors as the items for younger children.
Emotional support toward young children was measured with seven items from the ECLS-B $(\alpha=0.85)$. Items were scored on a 0 (never) to 5 (more than once a day) scale for how frequently fathers provided for their child's emotional needs, engaged in social support, and actively socialized their children. For fathers of older children, engagement was measured with six items from the NSFG scored on a 0 (not at all) to 4 (everyday) scale for frequency of listening to their child's concerns, discussing their daily activities, teaching them between right and wrong, teaching them cultural values, communicating about issues important to the child, and providing emotional support $(\alpha=0.84$ ).

Positive control taps paternal behaviors aimed at correcting children's behavior with noncoercive strategies (Yan \& Ansari, 2016). The four items for young children came from the parental discipline scales in the ECLS-B $(\alpha=0.72)$. Fathers were asked to indicate on a 0 (not at all likely) to 3 (very likely) scale of how likely it would be to discipline their child by giving them a time out, giving them extra chores, taking away privileges, or giving them a warning. For older children, nine items from the SECCYD's monitoring scale ( $\alpha=0.94)$ were used. These items were scored on a 0 (not at all) to 3 (everything) scale reflecting what fathers know about their children's whereabouts, actions, and friendship groups.

Harsh discipline toward young children was measured with four items adapted from the ECLS-B parental discipline scales $(\alpha=0.71)$. These items assess problematic disciplinary behaviors toward children (Altschul et al., 2016), asking fathers to indicate how likely they would be to spank, hit, or make fun of a child that was misbehaving on a four-point scale ranging from 0 (not at all likely) to 3 (very likely). Among older children, harsh discipline is measured with six items from the parental hostility scale included in the SECCYD. These items are scored on a 0 (never) to 3 (always) scale and ask fathers how frequently they criticize, shout/yell, threaten physical harm, grab/push/hit/shove, strike with a hand or object, or insult/swear at their child if they are misbehaving $(\alpha=0.90)$.

Caregiving was only measured among fathers of young children and comparable, developmentally appropriate measures of caregiving with older children were not available in the data. Seven items $(\alpha=0.85)$ asked how frequently fathers engaged in helping the child get ready 
for bed, bathe, change diaper/help with toileting, grooming, and other caregiving activities in the past week $(0=$ never to $4=$ everyday/almost everyday). Recently, scholars have called on a greater focus on father-child relationship quality, given its significance for a host of positive child outcomes (Palkovitz, 2019). Relationship quality items were only asked of fathers with children between 9 and 18 years of age $(\alpha=0.88)$. These items asked fathers how often $(0=$ always to $4=$ never $)$ they felt disappointed in their child, wished their child was different, felt proud of their child (reverse coded), felt anger/irritated with their child, tried to understand their child (reverse coded), and argued/fought with their child.

Key Independent Measures. Adverse childhood experiences were measured with the standardized instrument provided by the Centers for Disease Control and Prevention (Anda et al., 2010). This measure consists of nine items scored 0 (no) or 1 (yes), depending on whether respondents experienced the following prior to age 18: emotional abuse, physical abuse, sexual abuse, emotional neglect, physical neglect, witnessing domestic violence, a household member with a substance abuse problem, a mentally ill household member, or an incarcerated household member. Using standardized scoring procedures, the nine items were summed to generate a cumulative index of traumatic childhood experiences-ranging from 0 to 9. Exact question wording, the distribution of ACEs in our sample, and its comparability to other national samples are reported in Table 2.

We include two measures of psychological distress. Internalized distress consists of six measures from the Kessler-6 (K-6) and Center for Epidemiological Studies-Depression (CES-D) scales. All items were scored on a 0 (none of the time) to 3 (most of the time) scale for frequency in the past month. The items tapped: hopelessness, restlessness/feeling fidgety, everything taking effort, feeling worthless, feeling so depressed nothing helped change their mood, and anxiety $(\alpha=0.87)$. Items were summed to create a scale ranging between 0 and 18. Externalized distress was measured with five items used in both the externalized symptoms scale of the masculine depression scale (Magovcevic \& Addis, 2008) and the male symptoms scale in the National Comorbidity Study Replication (Martin et al., 2013). Participants indicated how frequently $(0=$ none or little of the time to $3=$ all the time) in the past month they yelled at people or things, got so angry they smashed or punched something, binge drank, used recreational drugs, and needed sex to feel better. Items were summed to create a scale ranging from 0 to $15(\alpha=0.85)$. The correlation between internalized and externalized distress is not problematically high at $r=0.51$.

Control Variables. Ecological models of fathering consider a broad range of factors that are associated with the father, his relationships, and broader context to understand levels of father involvement. Using this framework, we include several additional predictors that may help explain the association between ACEs, psychological distress, and fathering (Cabrera et al., 2014; Shafer et al., 2019; Umberson et al., 2014). Consistent with an ecological perspective, we group these control measures into paternal sociodemographic characteristics, father's history, and family/household relationships and attributes.

We controlled for a number of paternal characteristics in our models. Earlier, we noted the significance of masculine norm adherence for understanding the effects of ACEs, the manifestation of psychological distress, and father involvement. As a result, we used Mahalik et al.'s (2003) Conformity to Masculine Norms Inventory (CMNI) to measure masculine norm adherence. The CMNI consists of 22 items covering 11 masculine norm domains. Example items include "my work is the most important part of my life" and "I like to talk about my feelings" (reverse coded). Each item is measured on a 0 (strongly disagree) to 3 (strongly agree) scale and summed to create an overall score ranging from 0 to 66 that was standardized to a variable with a mean of 0 and an $S D$ of 1 . Higher scores are indicative of greater adherence to traditional masculine norms $(\alpha=0.79)$. In addition to racial and ethnic differences in fathering behavior discussed previously, BIPOC individuals are more likely to experience childhood adversity (Umberson et al., 2014) and severe psychological distress (Williams, 2018). Racial and ethnic identity was included as a set of dichotomous measures indicating if the respondent identified as non-Hispanic White, non-Hispanic Black/African-American, Latino/Hispanic, or another racial/ethnic identity (e.g., Asian/Asian-American, Indigenous, 
multiracial). Stress process models suggest that religion can be an important source of support that buffers the negative effects of both chronic and discrete stressors (Ellison \& Henderson, 2011). As a result, we include that a measure for father's religiosity was measured with the 11-item Centrality of Religiosity Scale (Huber \& Huber, 2012), which assesses both personal religiosity and participation in a religious community $(\mathrm{i}=0.96)$.

Several studies on childhood adversity and parenting include numerous sociodemographic characteristics as controls in their models (e.g., Brown et al., 2018). Consistent with this literature, we include many sociodemographic characteristics in our models. Father's age was measured continuously in years. Both ACEs and psychological distress are associated with socioeconomic status in adulthood (Nurius et al., 2015; Umberson et al., 2008, 2014). As a result, we include three measures of current socioeconomic status: father's education, a nine-category ordinal measure ranging from 0 (did not complete high school) to 8 (completed a graduate/professional degree); father's income in the past year was measured with an ordinal variable ranging from 0 (no income) to 11 (more than $\$ 300,000$ ). Each category was measured in a $\$ 20,000$ increment (i.e., $\$ 80,0001-\$ 100,000)$, except for the final two categories $(\$ 200,001-\$ 300,000$ and more than $\$ 300,000)$; and father's employment, a categorical measure indicating if the father was not employed for wages, works part-time (less than 35 hours per week), full-time (35-54 hours per week), or extreme hours (55+ hours per week). While the research on sexual minority fathers remains in its infancy (Averett, 2016), some evidence suggests that LGBTQ+ individuals are more frequently the target of abuse and neglect and tend to experience higher levels of psychological distress than heterosexual individuals (Schnarrs, 2019). Father's sexual identity was measured with a dichotomous measure indicting if the respondent's self-reported sexual identity was heterosexual or as gay, bisexual, transgendered, queer, or another sexual identity, such as asexual or pansexual $(1=G B T Q+)$. Notably, three respondents who identified as GBTQ+ indicated that their coparent as male and were removed from the final analysis because of small cell sizes. ACEs, psychological distress, and fathering behavior are strongly associated with physical health (Lehman et al., 2009;
Nurius et al., 2015; Shin et al., 2013; Shin \& Miller, 2012; Turney \& Hardie, 2018; Umberson et al., 2008). Father's health was measured using a global indicator, where respondents that indicated they were in fair or poor health were coded to indicate poor physical health, while the reference was good physical health (respondents who indicated excellent, very good, or good).

Our earlier discussion regarding paternal socialization and childhood adversity suggests that factors associated with paternal background are important controls that should be included in our models. How one's father parented is a particularly relevant consideration. As a result, we included six items from the Nurturant Fathering Scale (Finley \& Schwartz, 2004) to measure own father involvement. The items in this scale capture how emotionally supportive, involved, and warm the respondent's own father/father figure was $(\alpha=0.95)$. Socioeconomic disadvantage in one's FOO is also associated with increased risk for ACEs and psychological distress in adulthood (Umberson et al., 2008, 2014). As a result, respondents were asked to report their FOO income was measured with the same categories as current income, but asked respondents to provide an average estimate between the ages of 12 and 18 as a measure of family socioeconomic status.

Notably, ecological models place father involvement with a web of family, partner, and child characteristics. Childhood adversity and psychological distress are associated with family structure (Williams \& Finch, 2019) and child characteristics have been included as important controls on prior work linking ACEs and parenting (Widom et al., 2015). Measures focused on child demographics considered if the focal child was nonbiological $(1=$ nonbiological $)$ focal child gender $(1=$ female $)$, and focal child age, measured continuously in years. Life stressors like economic pressures, mental and physical health problems, and work-family conflict all impact how parents work together (Bronte-Tinkew et al., 2010; Turney \& Hardie, 2018)—suggesting a potential relationship with a chronic stressor like ACEs, as well. Indeed, mothers sometimes consciously or unconsciously mediate how depressed fathers interact with their children (Thomas \& Holmes, 2019). Perceived closed gatekeeping is drawn from Fagan and Barnett's (2003) scale and nine items scored on a 0 (strongly disagree) to 4 (strongly agree) scale. Example items 
include "if a decision has to be made for my child, the mother should make it, not me" and "if an adult needs to talk to my child, the mother should do it" ( $\alpha=0.95)$. Perceived coparenting quality was measured with five items drawn from the Fragile Families and Child Wellbeing Study $(\alpha=0.83)$. These items were scored on a three-point scale $(0=$ never to $2=$ always $)$. Sample items include "she respects the schedules and rules you make for the child" and "you and the mother talk about problems that come up with raising this child." Finally, parent relationship status is measured with a categorical variable that captures both residential status and relationship type. We include a categorical with six categories: first married to focal child mother (reference), remarried to focal child mother, cohabits with focal child mother, single and does not reside with focal child mother, married but does not reside with focal child mother, and divorce/separated and does not reside with focal child mother as the categories.

\section{Analytic Strategy}

We use two strategies to approach our research questions. We use Generalized Linear Models (GLM) with log-transformed responses in our analysis of the relationship between ACEs and psychological distress. Initial Ordinary Least Squares (OLS) regression models resulted in non-normally distributed residuals. We use the GLM approach (Lo \& Andrews, 2015) over alternative approaches for two reasons. One possible solution to this issue is to log-transform the outcomes and then run an OLS model. However, some statisticians argue that doing so results in biased coefficients (Silva \& Tenreyro, 2006). Other models, such as those developed for count outcomes, use Poisson or negative binomial modeling to address this issue. However, our outcomes do not represent a count of events, nor are they zero-inflated.

For the analysis of ACEs, psychological distress, and fathering behavior, we used seemingly unrelated regression (SUR) analyses that account for correlation between multiple mediators that might be problematic in alternative mediation modeling strategies (Hicks \& Tingley, 2011). Each SUR was modeled in three steps. First, internalized distress was regressed on ACEs and all control variables. Second, externalized distress was regressed in the same manner. Finally, the specific fathering behavior was regressed on both measures of distress, ACEs, and all control measures. After SURs were modeled, the direct effect of ACEs and the indirect effects of ACEs, through internalized and externalized distress, were calculated using the nonlinear combination of estimators (nlcom) command in Stata 16.0. Mediation was then tested in three ways: Sobel's test, 95\% bias-corrected confidence intervals with bootstrapped standard errors (SEs), and 95\% percentile-corrected confidence intervals with bootstrapped SEs (Preacher \& Hayes, 2008). Finally, since there are a small number of missing cases in our data (less than $3 \%$ total), we used multiple imputation techniques to preserve sample size. Results presented are combined from 20 imputed models and are substantively similar to models using listwise deletion.

We conducted several robustness checks. One potential issue with traditional ACE scoring methods is that they may do a poor job of addressing the severity of childhood adversity. For example, abuse and neglect may be more impactful than some aspects of household dysfunction. We tested this in two ways. First, we created continuous measures that separated out abuse/neglect and household problem scores. Second, we separated out abuse, neglect, and household problems into three scores. Both sets of models indicated that abuse and neglect were associated with increased internalized and externalized distress, negatively associated with the five of the six measures of positive fathering, and positively associated with the use of harsh discipline. Meanwhile, household problems were associated with both measures of distress, decreased warmth, increased use of harsh discipline, and reduced caregiving. A second issue is that ACEs can have either linear or nonlinear effects (Cavanaugh et al., 2015). We tested for this possibility with both continuous and categorical measures of ACEs $(0,1,2,3$, $4+)$. These models indicated the effects of ACEs more closely approximated nonlinear effects, as opposed to linear effects. As a result, we include the categorical measures in our final models.

\section{Results}

\section{Descriptive Statistics}

Summary statistics are reported in Table 1. As we noted earlier, we use age-group specific $z$-scores for four measures of father involvement, while the remaining two measures, although 
Table 1. Descriptive Statistics of the Sample $(\mathrm{n}=2,072)$

\begin{tabular}{|c|c|c|c|c|}
\hline & Mean/Prop. & $S D$ & Minimum & Maximum \\
\hline \multicolumn{5}{|l|}{ Fathering behaviors } \\
\hline Warmth & 0.008 & 0.98 & -4.82 & 1.265 \\
\hline Engagement & 0.039 & 0.953 & -3.509 & 2.258 \\
\hline Positive control & 0.033 & 0.968 & -4.335 & 1.95 \\
\hline Harsh discipline & 0.002 & 1.01 & -0.639 & 4.4 \\
\hline \multicolumn{5}{|l|}{ Adverse childhood experiences } \\
\hline 0 & 0.379 & & 0 & 1 \\
\hline 1 & 0.183 & & 0 & 1 \\
\hline 2 & 0.127 & & 0 & 1 \\
\hline 3 & 0.154 & & 0 & 1 \\
\hline $4+$ & 0.156 & & 0 & 1 \\
\hline \multicolumn{5}{|l|}{ Psychological distress } \\
\hline Internalized distress & 5.312 & 4.106 & 0 & 18 \\
\hline Externalized distress & 1.791 & 2.618 & 0 & 15 \\
\hline \multicolumn{5}{|l|}{ Paternal characteristics } \\
\hline Non-Hispanic White ${ }^{a}$ & 0.723 & & 0 & 1 \\
\hline Non-Hispanic Black & 0.097 & & 0 & 1 \\
\hline Hispanic/Latino & 0.113 & & 0 & 1 \\
\hline Other racial/ethnic identity & 0.067 & & 0 & 1 \\
\hline Father's age & 39.525 & 10.144 & 18 & 72 \\
\hline Father's educational attainment & 4.615 & 2.143 & 0 & 8 \\
\hline Father's current income & 3.824 & 2.125 & 0 & 11 \\
\hline Does not work for wages ${ }^{\mathrm{a}}$ & 0.096 & & 0 & 1 \\
\hline Works part-time & 0.183 & & 0 & 1 \\
\hline Works full-time & 0.54 & & 0 & 1 \\
\hline Works extreme hours & 0.182 & & 0 & 1 \\
\hline Father identifies as GBTQ+ & 0.045 & & 0 & 1 \\
\hline Poor health & 0.125 & & 0 & 1 \\
\hline \multicolumn{5}{|l|}{ Paternal history } \\
\hline Own father involvement & 13.658 & 10.049 & 0 & 36 \\
\hline Income in FOO & 3.263 & 1.994 & 0 & 11 \\
\hline \multicolumn{5}{|l|}{ Child and family characteristics } \\
\hline Focal child is nonbiological & 0.164 & & 0 & 1 \\
\hline Focal child is female & 0.421 & & 0 & 1 \\
\hline Focal child age & 8.484 & 4.786 & 2 & 17 \\
\hline Perceived closed gatekeeping & 11.077 & 7.639 & 0 & 36 \\
\hline Perceived coparenting & 6.032 & 2.407 & 0 & 10 \\
\hline First married to focal child mother ${ }^{\mathrm{a}}$ & 0.559 & & 0 & 1 \\
\hline Remarried to focal child mother & 0.109 & & 0 & 1 \\
\hline Cohabits with focal child mother & 0.170 & & 0 & 1 \\
\hline Single, DNR with focal child mother & 0.087 & & 0 & 1 \\
\hline Married, DNR with focal child mother & 0.031 & & 0 & 1 \\
\hline Divorced/separated, DNR with focal child mother & 0.044 & & 0 & 1 \\
\hline
\end{tabular}

${ }^{a}$ Reference category in regressions. DNR $=$ does not reside; FOO = family-of-origin.

measured within a single age group, were also standardized. Thus, each variable was coded to a mean of 0 and an $S D$ of 1 . Any differences from these standardized values for the grand mean are due to size differences in the age groups of children. Nevertheless, there is substantial variability in all four measures in our data. Means and proportions for all measures are also found in Table 1. Additional details on the measurement of ACEs within SCF and how it compares 
Table 2. Generalized Linear Models of Internalized and Externalized Distress ( $\mathrm{n}=2,069)$

\begin{tabular}{|c|c|c|c|c|}
\hline & \multicolumn{2}{|c|}{ Internalized distress } & \multicolumn{2}{|c|}{ Externalized distress } \\
\hline & $e(B)$ & $S E$ & $e(B)$ & $S E$ \\
\hline $1 \mathrm{ACE}$ & 1.297 & $0.053 * * *$ & 1.274 & $0.105 * *$ \\
\hline 2 ACEs & 1.395 & $0.062 * * *$ & 1.776 & $0.137 * * *$ \\
\hline 3 ACEs & 1.510 & $0.073 * * *$ & 1.846 & $0.158 * * *$ \\
\hline $4+$ ACEs & 1.575 & $0.059 * * *$ & 2.209 & $0.140 * * *$ \\
\hline Masculine norm adherence & 1.085 & $0.015^{* * * *}$ & 1.219 & $0.029 * * *$ \\
\hline Non-Hispanic Black & 1.038 & 0.042 & 1.221 & $0.073 * *$ \\
\hline Hispanic/Latino & 0.923 & 0.038 & 1.020 & 0.055 \\
\hline Other racial/ethnic identity & 0.980 & 0.052 & 0.964 & 0.088 \\
\hline Father's age & 0.933 & $0.016^{* * * *}$ & 0.807 & $0.026^{* * * *}$ \\
\hline Father's educational attainment & 1.015 & 0.016 & 1.028 & 0.026 \\
\hline Father's current income & 0.935 & $0.017 * * *$ & 0.980 & 0.030 \\
\hline Works part-time & 0.939 & 0.043 & 0.959 & 0.061 \\
\hline Works full-time & 0.972 & 0.031 & 0.995 & 0.053 \\
\hline Works extreme hours & 0.941 & 0.039 & 0.894 & 0.063 \\
\hline Father identifies as GBTQ+ & 0.888 & $0.049 *$ & 0.901 & 0.069 \\
\hline Poor health & 1.292 & $0.041 * * *$ & 1.210 & $0.071 * *$ \\
\hline Own father involvement & 0.991 & 0.014 & 0.940 & $0.021 * *$ \\
\hline Income in FOO & 1.026 & 0.015 & 1.017 & 0.023 \\
\hline Focal child is nonbiological & 1.008 & 0.049 & 0.993 & 0.070 \\
\hline Focal child is female & 0.984 & 0.026 & 1.058 & 0.047 \\
\hline Focal child age & 1.008 & 0.016 & 1.057 & $0.026^{*}$ \\
\hline Perceived gate closing & 1.059 & $0.014 * * *$ & 1.228 & $0.028 * * *$ \\
\hline Perceived coparenting & 0.906 & $0.011^{* * * *}$ & 0.883 & $0.017 * * *$ \\
\hline Remarried to focal child mother & 1.027 & 0.048 & 0.878 & 0.095 \\
\hline Cohabits with focal child mother & 0.975 & 0.033 & 0.935 & 0.046 \\
\hline Single, DNR with focal child mother & 0.972 & 0.044 & 0.832 & $0.062 *$ \\
\hline Married, DNR with focal child mother & 0.989 & 0.071 & 0.980 & 0.110 \\
\hline Divorced/separated, DNR with focal child mother & 0.997 & 0.054 & 0.962 & 0.091 \\
\hline Constant & 3.681 & 0.912 & & \\
\hline AIC & 5.253 & & 4.494 & \\
\hline $\mathrm{BIC}$ & $6,855.4$ & & $5,066.0$ & \\
\hline
\end{tabular}

$\mathrm{ACE}=$ adverse childhood experience; $\mathrm{AIC}=$ akaike information criterion; $\mathrm{BIC}=$ bayesian information criterion; $\mathrm{DNR}=$ does not reside $\mathrm{FOO}=$ family-of-origin. ${ }^{* * *} p<.001 . * * p<.01 . * p<.05$ (two-tailed tests).

to other commonly used samples of ACEs in the United States are reported in Appendix A.

\section{Psychological Distress}

Results from the generalized linear models for internalized and externalized psychological distress are reported in Table 2. Internalized distress, reported in the left-hand column, is associated with ACEs. Fathers with an ACE score of 1 had internalized distress scores $28.7 \%$ higher, on average, than fathers who did not experience ACEs $(p<.001)$. Internalized distress rose with ACEs. Compared to those with no ACEs, fathers with two, three, and four or more ACEs had scores that were 39.5\%, 51.0\%, and $57.5 \%$ higher, respectively (all effects are $p<.001)$. Masculine norm adherence, which was standardized for this model, was also significantly associated with internalized distress. A $1 S D$ increase in masculine norm adherence was associated with an $8.5 \%$ increase in internalized distress $(p<.001)$. As shown in the right-hand column, both ACEs and masculine norm adherence were significantly associated with externalized distress. Fathers with an ACE score of 1 had externalized distress scores $27.4 \%$ higher than fathers with an ACE score of $0(p<.001)$. Comparable effects for fathers with 
ACE scores 2 and 3 were $77.6 \%$ and $84.6 \%$, respectively (both effects at $p<.001$ ). Fathers who had scores of 4 or greater had particularly high externalized distress scores. Indeed, they were 1.109 times greater, on average, than that of the fathers with no ACEs $(p<.001)$. Finally, providing evidence for gendered response, a $1 S D$ increase in masculine norm adherence was associated with a $23.6 \%$ increase $(p<.001)$.

Across models, there was consistency in control variables and their relationship with psychological distress. Age was negatively associated with both measures of psychological distress, as was better perceived coparenting. Poor health and maternal gate closing were positively associated with both outcomes. Income and GBTQ+ were negatively associated with internalized distress, while increased paternal involvement in childhood was associated with lower externalized distress scores. Black fathers, meanwhile, reported higher average externalized distress scores than White fathers.

\section{Fathering Behavior}

Results from the SURs for fathering behavior are provided in Table 3. To assess the magnitude of effects, all reported coefficients are standardized. Because outcome variables are standardized, all dichotomous independent variables represent standardized differences between the predictor and its reference category. We found that, compared to fathers with no ACEs, fathers with ACE scores of 3 or greater were less engaged in positive fathering and more frequently used harsh discipline. For example, fathers with ACE scores of 3 had warmth scores that were $0.174 S D s$ lower, on average, than fathers with ACE scores of $0(p<.01)$. Similar sized negative effects were observed for emotional support, positive control, caregiving, and relationship quality. Generally, scores of 4 or greater had more substantial negative effects. Consider, as an example, the relationship between ACEs and caregiving. Fathers with scores of 4 or greater had caregiving scores that were, on average, $0.228 S D s$ lower than the scores reported by fathers with scores of 0 $(p<.001)$. Harsh discipline, unlike the other outcomes, is a negative parenting behavior and higher scores are considered poorer. For example, fathers with ACE scores of 3 have harsh discipline scores that are 0.226 SDs higher, on average, than the scores of fathers reporting no ACEs $(p<.001)$. The analogous difference for fathers with scores of 4 or greater is $0.368 S D s(p<.001)$. For only one outcome, there was an effect for fathers with an ACE score of 2. Fathers who experienced two ACEs had caregiving scores $0.176 S D s$ lower, on average, than fathers who reported no ACEs $(p<.01)$.

Internalized psychological distress was associated with five of the fathering outcomes. The relationship was strongest for caregiving $(B=-0.161, p<.001)$, followed by warmth $(B=-0.135, p<.001)$, father-child relationship quality $(B=-0.120, p<.01)$, and emotional support $(B=-0.101, p<.001)$. Internalized distress was also positively associated with the use of harsh discipline, where a $1 S D$ increase was associated with a $0.079 S D$ increase in its use $(p<.01)$. Overall, internalized distress had stronger associations with fathering behavior than externalized distress-which was significantly associated with two of the six outcomes. In both cases, however, the coefficient for externalized distress was slightly larger than corresponding coefficient for internalized distress. A $1 S D$ increase in externalized distress was associated with a $0.139 S D$ decrease in relationship quality $(p<.001)$ and a $0.201 S D$ increase in the use of harsh discipline $(p<.001)$.

Several other covariates were significantly associated with fathering. Masculine norm adherence was associated with all outcomes but positive control and most strongly related with the use of harsh disciplinary techniques $(B=0.207, p<.001)$. Among paternal characteristics, Black fathers in the sample reported higher positive control and harsh discipline than their White counterparts. Religiosity was associated with positive parenting and the use of harsh discipline, while poor health seemed to be limiting for fathers, who reported lower warmth, emotional support, positive control, and caregiving than healthier counterparts. We find some support for intergenerational effects in father involvement. Own father involvement was positively associated with positive fathering outcomes and negatively related to the use of harsh discipline. Family characteristics were also significantly related to fathering, as well. Father involvement tends to decrease with child age and fathers tend to be warmer and less harsh toward their daughters than sons. Fathers that perceived closed gatekeeping by mothers reported significant lower levels of father involvement, with coefficients ranging 


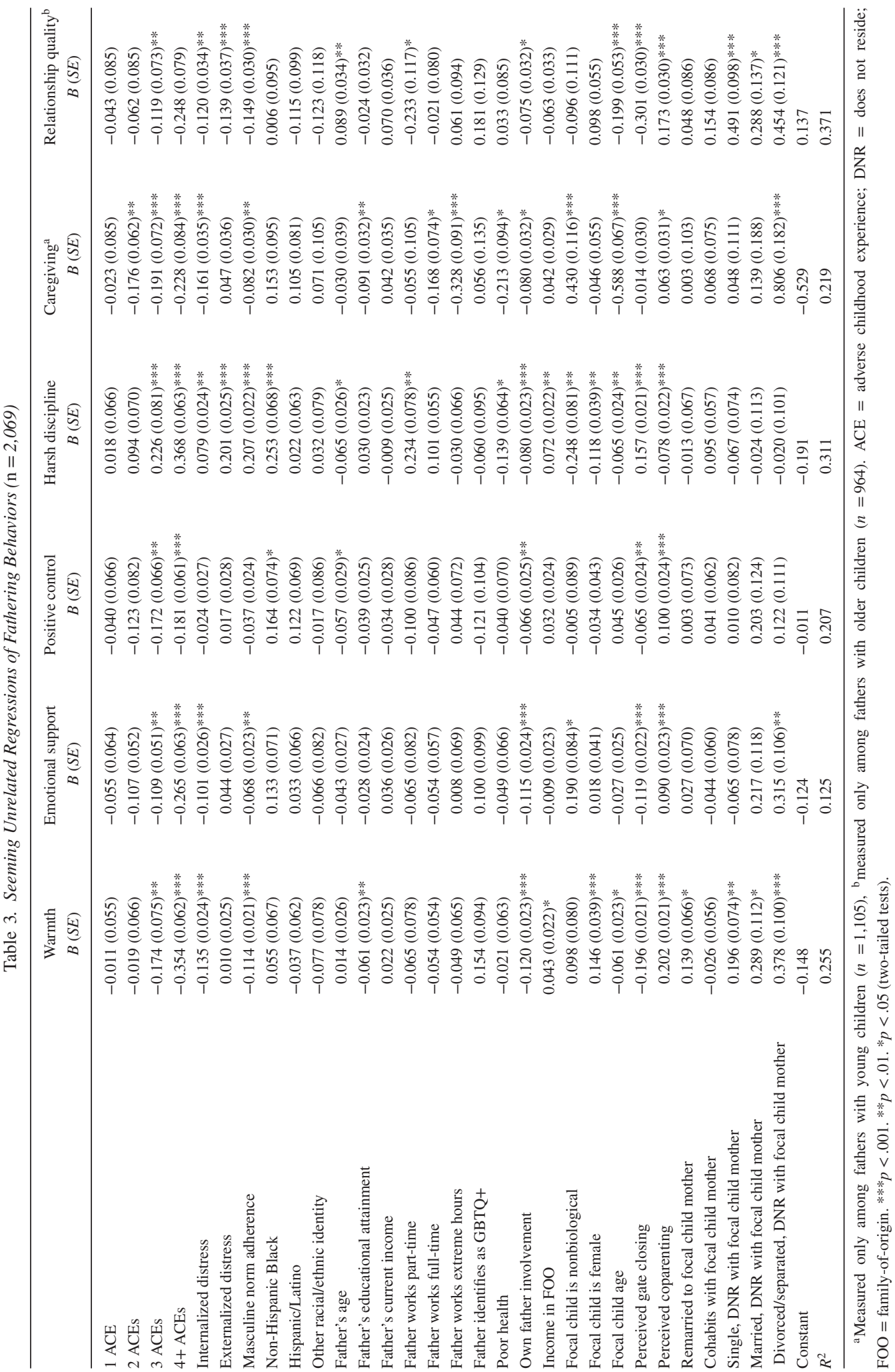


Table 4. Decomposition of Indirect Effects of Internalized and Externalized Distress on Fathering

\begin{tabular}{|c|c|c|c|c|c|c|}
\hline & Warmth & $\begin{array}{l}\text { Emotional } \\
\text { support }\end{array}$ & $\begin{array}{l}\text { Positive } \\
\text { control }\end{array}$ & $\begin{array}{c}\text { Harsh } \\
\text { discipline }\end{array}$ & Caregiving & $\begin{array}{c}\text { Relationship } \\
\text { quality }\end{array}$ \\
\hline \multicolumn{7}{|c|}{ Internalized distress } \\
\hline $1 \mathrm{ACE}$ & -0.038 & -0.007 & -0.002 & 0.028 & -0.019 & -0.007 \\
\hline 2 ACEs & -0.044 & -0.020 & -0.003 & 0.041 & $-0.032 \mathrm{abc}$ & -0.014 \\
\hline 3 ACEs & $-0.055 \mathrm{abc}$ & $-0.047 \mathrm{abc}$ & -0.003 & $0.055 \mathrm{abc}$ & $-0.038 \mathrm{abc}$ & $-0.043 \mathrm{abc}$ \\
\hline 4+ ACEs & $-0.174 \mathrm{abc}$ & $-0.089 a b c$ & -0.009 & $0.061 \mathrm{abc}$ & $-0.054 \mathrm{abc}$ & $-0.053 \mathrm{abc}$ \\
\hline Total & $-0.311 \mathrm{abc}$ & $-0.163 a b c$ & -0.017 & $0.185 \mathrm{abc}$ & $-0.143 a b c$ & $-0.117 \mathrm{abc}$ \\
\hline \multicolumn{7}{|c|}{ Externalized distress } \\
\hline $1 \mathrm{ACE}$ & -0.001 & -0.003 & -0.006 & 0.013 & -0.001 & -0.016 \\
\hline 2 ACEs & -0.004 & -0.008 & -0.007 & 0.031 & -0.002 & -0.024 \\
\hline 3 ACEs & -0.005 & -0.013 & -0.011 & $0.071 \mathrm{abc}$ & -0.004 & $-0.043 a b c$ \\
\hline 4+ ACEs & -0.007 & -0.024 & -0.025 & $0.115 \mathrm{abc}$ & -0.008 & $-0.062 \mathrm{abc}$ \\
\hline Total & -0.017 & -0.048 & -0.049 & $0.230 \mathrm{abc}$ & -0.015 & $-0.145 a b c$ \\
\hline$\%$ mediated & $32.9 \%$ & $31.0 \%$ & $7.0 \%$ & $51.8 \%$ & $43.9 \%$ & $49.8 \%$ \\
\hline
\end{tabular}

Notes. Mediation analysis from seemingly unrelated regression models shown in Table 3; a = Mediation is statistically significant $(p<.05)$ using Sobel's test; $\mathrm{b}=$ mediation statistically significant $(p<.05)$ using 95\% bias-corrected confidence intervals; $\mathrm{c}=$ mediation statistically significant $(p<.05)$ using $95 \%$ percentile-corrected confidence intervals; $\mathrm{n} / \mathrm{s}=$ mediation not statistically significant. ACE, adverse childhood experience.

between -0.065 for positive control to -0.196 for warmth. Closed gatekeeping also is significantly related to father-child relationship quality $(B=-0.301, p<.001)$. In contrast, perceptions of coparenting quality had substantially positive effects on men's fathering, particularly with respect to warmth, caregiving, and father-child relationship quality.

\section{Mediating Effects}

Table 4 reports the decomposed indirect effects of internalized and externalized distress for each fathering behavior. These estimates are the result of the SUR models reported in Table 3. ACEs were partially, but significantly, mediated by internalized distress for five of the six outcomes. Notably, significant mediation took place at three and four or more ACEs in each case, except for caregiving where two ACEs was also a significant mediator. Externalized distress was also a significant mediator for two outcomes: harsh discipline and father-child relationship quality. In both instances, the mediating influence of externalized distress was slightly larger than the analogous effect of internalized distress. Across outcomes, the two measures of psychological distress accounted for between $31.0 \%$ (emotional support) and $51.8 \%$ (harsh discipline) of the relationship between childhood adversity and fathering. Across outcomes, internalized distress accounted for $22.9 \%$ (emotional support) to $36.7 \%$ (caregiving) of the relationship between childhood adversity and fathering.

\section{Discussion AND CONCLUSION}

Childhood adversity and trauma have wide and long-lasting effects on the individuals who experience them (Anda et al., 2010), including how they parent their children (Widom et al., 2015; Williams \& Finch, 2019). This literature, however, has three limitations addressed by this article. First, most studies have considered how individual ACEs, such as experiencing physical abuse or neglect, may be linked to the intergenerational transmission of child maltreatment. Using such an approach does not consider the potential pernicious influence of accumulated adversity. Second, and relatedly, the focus on child maltreatment does not consider the broader and more diverse range of things parents do for and with children. Maltreatment, although of extreme import, is an exceptionally negative action which does not address the possibility that ACEs are associated with an absence of positive and an abundance of negative parenting behaviors, which fall well short of the standard for maltreatment. Third, fathers are comparatively absent from the literature on childhood adversity and parenting. Yet, fathers positively influence their children, are more involved, and are engaged in parenting than ever before, and gender differences in ACEs and their effects 
on various outcomes have been documented in prior work (Holmes et al., 2010; Umberson et al., 2014). We addressed these gaps in the literature by using an ecological model of father involvement (Cabrera et al., 2014), treating ACEs as stressful distal events associated with six fathering behaviors. Furthermore, we integrated literature suggesting that ACEs may work through proximate psychological distress to influence men's parenting.

ACEs had direct, negative associations with expressive parenting behaviors like warmth, emotional support, and relationship quality. Similar associations were observed with instrumental parenting, including increased use of harsh discipline. Although we do not explicitly include mothers' ACEs in our study, comparisons between our results and those from that literature suggest that there may be important gender differences in this relationship. Despite significant methodological, conceptual, and operational diversity in the extant literature, several studies find that maternal childhood abuse and neglect are associated with elevated negative parenting practices, such as open hostility, emotional withdrawal, and overly critical assessment of children (Khan \& Renk, 2019; Kolomeyer et al., 2016; Thornberry et al., 2012). We used harsh disciplinary practices, ranging from yelling/screaming to spanking and hitting misbehaving children, to capture negative parenting. Like studies focused on mothers, we found that fathers were more likely to engage in negative behaviors as their ACE scores increased. Notably, we found that fathering was influenced at high ACE scores, a result common across outcomes in the ACEs literature (Chapman et al., 2011; Feliti et al., 1998). Across all outcomes, ACE scores of 3 or greater were associated with poorer paternal behaviors. These results suggest that there are important cumulative effects of childhood adversity and trauma that affect how men undertake both instrumental and expressive parenting. This relationship may result from socializing influences where parents see their own parents' behaviors as normative and contextual constraints that are particularly crucial for men's parenting.

Work considering the relationship between maternal ACEs and positive parenting behaviors tends to yield mixed results. Few studies find a negative relationship, while the majority report null findings. Qualitative work notes that many mothers work hard to break intergenerational patterns of abuse and neglect, but tend to focus more on avoiding negative parenting, rather than amplifying positive behaviors (Herbell et al., 2020). Quantitative work, using a variety of sampling strategies, tends to find that childhood adversity has no relationship with mothers' instrumental parenting (Khan \& Renk, 2019; Kolomeyer et al., 2016; Thornberry et al., 2012). In our study of fathers, we find that ACEs are negatively associated with both instrumental and expressive parenting. These divergent findings may be the result of gender differences in ecological sensitivity. There may be no effect among mothers because of the strong socializing influences around motherhood, beginning in childhood and extending well into adulthood. The uneven division of household labor, cultural norms around childcare, and institutional forces place primary responsibilities for child health, development, and well-being squarely on the shoulders of women (Bianchi et al., 2006; Collins, 2019). In this same vein, we found no relationship between positive control, a measure of paternal engagement in discipline and monitoring, and ACEs. This suggests that gendered expectations of parenting play an important role in shaping parenting for men, as well.

At the same time, the lack of socializing influences toward expressive and instrumental parenting, few institutional supports, and negative childhood experiences appears to result in wide-ranging effects in fathers, who tend to be evaluated by different criteria than mothers (Scheibling, 2018; Schoppe-Sullivan $\&$ Fagan, 2020). The significance of individual, institutional, and cultural forces for men's parenting, combined with the negative impact of childhood adversity, may help explain why we find more significant effects among fathers than are present in the literature on ACEs and mothering. Future work would do well to consider this question by undertaking gender comparisons of these effects, both within and between cultural contexts. Unfortunately, data availability problems make this a difficult question to answer at present.

The relationship between high ACE scores and fathering behavior was partially mediated by psychological distress. Based on gender response models, which suggest that men and women often react to stressors and mental health issues in socialized ways, we included measures for internalized and externalized distress in our models. ACEs were predictive of both, 
although the relationship was slightly stronger for externalized distress. Internalized distress was significantly associated with five of the six fathering outcomes, while externalized distress was only associated with the use of harsh discipline and father-child relationship quality. Overall, psychological distress mediated all fathering behaviors save positive control. These effects were largely driven by internalized distress, although the mediating effect of externalized distress was stronger for two outcomes. These results add to the small, but growing body of research documenting that mental health is associated with harsh, withdrawn, or insensitive parenting behaviors and decreases in positive parenting among fathers (Wilson \& Durbin, 2010). These results for externalized distress may be particularly valuable. Although studies of internalized distress are relatively ubiquitous in the literature, we found externalized distress was associated with, arguably, the two most emotive fathering behaviors considered in our study. These results underscore the need to consider gendered response to stressors in future research on parenting and mental health-particularly when studying fathers.

Although we find significant mediation, ACEs had persistently significant direct effects across all six outcomes. In an effort to account for residual links between ACEs and fathering behavior, we considered multiple sets of covariates. First, we considered numerous aspects of fathers' adult life that are associated with ACEs, including health, socioeconomic status, timing of childbearing, and marital status. Second, we studied historical factors that are associated with a disproportionate risk of experiencing childhood adversity and trauma (Umberson et al., 2014). Finally, we situated fathers within an ecological context by considering how maternal, child, and family traits may influence whether men experience elevated levels of psychological distress and how they parent their children. Because of data limitations, we cannot include every potential mechanism or variable associated with ACEs or fathering. For example, we cannot include measures to consider if maternal ACEs or mental health interacts with paternal childhood adversity and psychological distress to shape men's parenting. From an ecological perspective, these may be important predictors of fathering - particularly in light of research which shows significant spillover of stress and distress between parents
(Goodman et al., 2014). Notably, our data are not unique in this limitation and future work would do well to attend to such issues. Nevertheless, the relationship between ACEs and fathering behavior is robust to the inclusion of a myriad of controls, indicating that they are across chronic stressors with life-long effects on how individuals function in their various roles and responsibilities (Williams \& Finch, 2019).

Despite the significance of these findings, there are important limitations that should be considered when reviewing our results. First, SCF is a cross-sectional study, meaning that the chronicity of ACEs' relationship with psychological distress could not be modeled. ACEs may be associated with chronic distress, leading to more substantial negative effects on positive fathering. Second, SCF is a national quota sample and is not randomized. Although the demographic estimates (i.e., race/ethnicity, education, residential status, and income) for the full SCF sample are similar to those in other data sets used to study fatherhood, some groups such as low-SES and BIPOC fathers, are underrepresented in SCF. Third, we used a standardized measure of ACEs from the CDC. This measure allows researchers to address and assess potentially traumatic and difficult childhood experiences. However, it is limited by how individuals interpret such events or if they accurately recall the details of their childhood. Furthermore, our measure of ACEs does not address the severity or frequency of each childhood experience-a problem common in studies focused on childhood trauma and adversity (Colman et al., 2016).

Finally, our measures of father involvement rely on reports from fathers themselves. Paternal reports of their behavior may be biased by overreporting their involvement or underreporting negative behaviors. For example, highly distressed fathers or fathers with high ACE scores may view their parenting as poor, due to their psychological state and/or childhood histories, resulting in reports consistent with this view of themselves. Importantly, some studies indicate that all members of a family have unique, but overlapping views of father involvement (Dyer et al., 2014). At the same time, research from the work-family conflict literature suggests that maternal reports often reflect how mothers think their partners should feel and behave, not their actual feelings and behaviors (Nomaguchi \& Milkie, 2017). Although multiple perspectives of paternal behavior would be helpful, we know 
of no data set that provides such measurement of father involvement, while also including measures of ACEs and psychological distress.

Despite these limitations, our article has important practical and research applications. Practically, preventative public health efforts could focus on the inclusion of modules on childhood trauma and psychological distress in parenting courses offered through school districts, university extension programs, or by other organizations. These efforts could focus on the importance of warmth, engagement, and positive disciplinary techniques through an awareness of how one's childhood history (ACEs) can influence parenting behaviors. An understanding of ACEs in venues that fathers frequent, such as pediatrician or OB-GYN offices in the prenatal period, may also prove useful in public health efforts. In areas of treatment, a discussion of or an evaluation of ACEs in both parents may help individuals improve on their parenting. Overall, public policy initiatives, such as responsible fatherhood programs offered by local organizations via federal grants, may be limited in their success among fathers with untreated childhood trauma and mental health issues. Indeed, current public discourse blames bad fathers for a myriad of social ills-from gun violence to crime to the so-called "death of men" (Edin \& Nelson, 2013). Such discourse does little to understand how chronic stressors, like childhood trauma and adversity, shape men's parenting. Our findings contribute to the scholarship of others (Umberson et al., 2014), highlighting the need for public discourse and public policy to account for the influence of childhood adversity on adult life chances, child outcomes, and the intergenerational transmission of advantage/disadvantage.

In addition to the questions posed throughout this discussion, our article underscores the need for more research addressing ACEs and parenting - both among mothers and fathers. Researchers know little about how the cumulative effects of childhood adversity influence parenting and how they may affect child psychological, social, developmental, and cognitive outcomes. While prior work has considered the influence of childhood sexual abuse, physical abuse, or neglect on parenting and child outcomes, little work has linked a cumulative measure of ACEs to child well-being. Our results also suggest that the relationship between ACEs and parenting is complex. As a result, future research should consider additional mediators of the relationship between childhood trauma and parenting, including factors such as posttraumatic stress, parenting stress, and other mental health issues. Moreover, given persistent inequalities that act as stressors themselves, future work would do well to consider potential moderators such as racial/ethnic identity, socioeconomic status, employment, and social capital - all of which are important resources for involved fathering (Palkovitz, 2019). Given our findings related to gendered response in distress, masculine norm adherence may be another significant mediator of these relationships. Finally, future work would do well to look at additional parenting behaviors and consider how maternal and paternal ACEs shape parenting in direct comparative analyses.

In conclusion, we found that ACEs are associated with how men parent their children, although this relationship was partially mediated by more proximate measures of distress. Thus, it appears that ACEs have both direct and indirect relationships with fathering behavior. Our findings are strengthened by our use of a large, national sample, the use of multiple parenting measures, the use of two measures of psychological distress, and our ability to address variability in parenting across child age. As a result, this article is one of the first to address the question of childhood adversity and men's parenting among a diverse group of fathers. Overall, our results suggest that ACEs are important and represent an issue worthy of further investigation by scholars interested in how life course events shape fathering and life chances, the influence of ACEs in adulthood, the perpetuation of problematic parenting across generations, and the contribution of fathers in families.

\section{SUPPORTING INFORMATION}

Additional supporting information may be found online in the Supporting Information section at the end of the article.

Appendix S1: Supplementary Information

\section{REFERENCES}

Adamsons, K., \& Pasley, K. (2016). Parents' fathering identity standards and later father involvement. Journal of Family Issues, 37(2), 221-244. https:// doi.org/10.1177/0192513X13514407 
Addis, M. E. (2008). Gender and depression in men. Clinical Psychology: Science and Practice, 15(3), 153-168.

Altschul, I., Lee, S. J., \& Gershoff, E. T. (2016). Hugs, not hits: Warmth and spanking as predictors of child social competence. Journal of Marriage and Family, 78(3), 695-714. https://doi.org/10.1111/ jomf.12306

Anda, R. F., Butchart, A., Felitti, V. J., \& Brown, D. W. (2010). Building a framework for global surveillance of the public health implications of adverse childhood experiences. American Journal of Preventive Medicine, 39(1), 93-98. https://doi .org/10.1016/j.amepre.2010.03.015

Averett, K. H. (2016). The gender buffet: LGBTQ parents resisting heteronormativity. Gender \& Society, 30(2), 189-212.

Bar-On, I. K., \& Scharf, M. (2016). The reconstruction of fatherhood across two generations: From experiences of deficiency, strictness, precocious maturity, and distance to indulgence, permissiveness, and intimacy. Journal of Family Issues, 37(5), 645-670. https://doi.org/10.1177/ $0192513 X 14528712$

Becker, J. B., McClellan, M., \& Reed, B. G. (2016). Sociocultural context for sex differences in addiction. Addiction Biology, 21(5), 1052-1059. https:// doi.org/10.1111/adb.12383

Bianchi, S. M., Robinson, J. P., \& Milkie, M. A. (2006). Changing rhythms of American family life. Russell Sage Foundation.

Bouchard, G. (2012). Intergenerational transmission and transition to fatherhood: A mediated-moderation model of paternal engagement. Journal of Family Psychology, 26(5), 747-755. https://doi.org/10.1037/a0029391

Bronte-Tinkew, J., Moore, K. A., Matthews, G., \& Carrano, J. (2007). Symptoms of major depression in a sample of fathers of infants: Sociodemographic correlates and links to father involvement. Journal of Family Issues, 28, 61-99.

Bronte-Tinkew, J., Horowitz, A., \& Carrano, J. (2010). Aggravation and stress in parenting: Associations with coparenting and father engagement among resident fathers. Journal of Family Issues, 31(4), 525-555. https://doi.org/10.1177/ 0192513 X09340147

Brown, G. L., Kogan, S. M., \& Cho, J. (2020). Pathways linking childhood trauma to rural, unmarried, African American father involvement through oxytocin receptor gene methylation. Developmental Psychology, 56(8), 1496-1508. https://doi.org/ 10.1037/dev0000929

Brown, G. L., Kogan, S. M., \& Kim, J. (2018). From fathers to sons: The intergenerational transmission of parenting behavior among African American Young men. Family Process, 57(1), 165-180. https://doi.org/10.1111/famp.12273
Cabrera, N. J., Fitzgerald, H. E., Bradley, R. H., \& Roggman, L. (2014). The ecology of father-child relationships: An expanded model. Journal of Family Theory \& Review, 6, 336-354.

Cabrera, N. J., Volling, B. L., \& Barr, R. (2018). Fathers are parents, too! Widening the lens on parenting for children's development. Child Development Perspectives, 12(3), 152-157. https://doi.org/ 10.1111/cdep. 12275

Call, J. B., \& Shafer, K. (2018). Gendered manifestations of depression and help seeking among men. American Journal of Men's Health, 12(1), 41-51.

Cavanaugh, C. E., Petras, H., \& Martins, S. S. (2015). Gender-specific profiles of adverse childhood experiences, past year mental and substance use disorders, and their associations among a national sample of adults in the United States. Social Psychiatry and Psychiatric Epidemiology, 50, 1257-1266. https://doi.org/10.1007/s00127-0151024-3

Center for Disease Control and Prevention. (2019). Behavioral risk factor surveillance system ACE data. Violence Prevention. https://www.cdc .gov/violenceprevention/childabuseandneglect/ acestudy/ace-brfss.html

Centers for Disease Control and Prevention. (2010). Adverse childhood experiences reported by adults-five states, 2009. Morbidity and Mortality Weekly Report, 59(49), 1609-1613.

Chapman, D. P., Whitfield, C. L., Felitti, V. J., Dube, S. R., Edwards, V. J., \& Anda, R. F. (2004). Adverse childhood experiences and the risk of depressive disorders in adulthood. Journal of Affective Disorders, 82(2), 217-225. https://doi .org/10.1016/j.jad.2003.12.013

Chapman, D. P., Wheaton, A. G., Anda, R. F., Croft, J. B., Edwards, V. J., Liu, Y., Sturgis, S. L., \& Perry, G. S. (2011). Adverse childhood experiences and sleep disturbances in adults. Sleep medicine, 12(8), 773-779.

Cheong, E. V., Sinnott, C., Dahly, D., \& Kearney, P. M. (2017). Adverse childhood experiences (ACEs) and later-life depression: Perceived social support as a potential protective factor. BMJ Open, 7(9), e013228. https://doi.org/10.1136/bmjopen2016-013228

Coates, E. E., \& Phares, V. (2014). Predictors of paternal involvement among nonresidential, Black fathers from low-income neighborhoods. Psychology of Men \& Masculinity, 15(2), 138-151. https:// doi.org/10.1037/a0032790

Collins, C. (2019). Making motherhood work: How women manage careers and caregiving. Princeton University Press.

Colman, I., Kingsbury, M., Garad, Y., Zeng, Y., Naicker, K., Patten, S., Jones, P. B., Wild, T. C., \& Thompson, A. H. (2016). Consistency in adult 
reporting of adverse childhood experiences. Psychological Medicine, 46(3), 543-549. https://doi .org/10.1017/S0033291715002032

Crouch, E., Radcliff, E., Strompolis, M., \& Wilson, A. (2018). Adverse childhood experiences (ACEs) and alcohol abuse among South Carolina adults. Substance Use \& Misuse, 53(7), 1212-1220. https://doi.org/10.1080/10826084.2017.1400568

Daly, K. J. (1996). Spending time with the kids: Meanings of family time for fathers. Family Relations, 45, 466-476. https://doi.org/10.2307/ 585177

DiLillo, D., Tremblay, G. C., \& Peterson, L. (2000). Linking childhood sexual abuse and abusive parenting: The mediating role of maternal anger. Child Abuse \& Neglect, 24(6), 767-779. https://doi .org/10.1016/S0145-2134(00)00138-1

Doucet, A. (2006). Do men mother? Fathering, care, and domestic responsibility. Do men mother? Fathering, care, and domestic responsibility. University of Toronto Press, Scholarly Publishing Division.

Doucet, A. (2014). Gender roles and fathering. In N. J. Cabrera, \& C. S. Tamis-LeMonda (Eds.), Handbook of father involvement: Multidisciplinary perspectives (pp. 297-319). Routledge.

Dube, S. R., Felitti, V. J., Dong, M., Chapman, D. P., Giles, W. H., \& Anda, R. F. (2003). Childhood abuse, neglect, and household dysfunction and the risk of illicit drug use: The adverse childhood experiences study. Pediatrics, 111(3), 564-572. https://doi.org/10.1542/peds.111.3.564

Dyer, W. J., Day, R. D., \& Harper, J. M. (2014). Father involvement: Identifying and predicting family members' shared and unique perceptions. Journal of Family Psychology, 28(4), 516-528. https://doi .org/10.1037/a0036903

Dyer, W. J., Kauffman, R., Fagan, J., Pearson, J., \& Cabrera, N. (2018). Measures of father engagement for nonresident fathers. Family Relations, 67(3), 381-398. https://doi.org/10.1111/fare .12317

Easton, S. D. (2014). Masculine norms, disclosure, and childhood adversities predict long-term mental distress among men with histories of child sexual abuse. Child Abuse and Neglect, 38(2), 243-251. https://doi.org/10.1016/j.chiabu.2013.08.020

Edin, K., \& Nelson, T. J. (2013). Doing the best I can: Fatherhood in the inner city. University of California Press.

Ellison, C. G., \& Henderson, A. K. (2011). Religion and mental health: Through the lens of the stress process. In A. J. Blasi (Ed.), Religion and Health, pp. 11-44. Leiden, The Netherlands: Brill.

Fagan, J., \& Barnett, M. (2003). The relationship between maternal gatekeeping, paternal competence, mothers' attitudes about the father role, and father involvement. Journal of Family
Issues, 24(8), 1020-1043. https://doi.org/10.1177/ 0192513 X03256397

Fagan, J., Day, R. D., Lamb, M. E., \& Cabrera, N. J. (2014). Should researchers conceptualize differently the dimensions of parenting for fathers and mothers? Journal of Family Theory \& Review, 6(4), 390-405.

Fagan, J., \& Palkovitz, R. (2011). Coparenting and relationship quality effects on father engagement: Variations by residence, romance. Journal of Marriage and Family, 73(3), 637-653. https://doi.org/ 10.1111/j.1741-3737.2011.00834.x

Felitti, V. J., Anda, R. F., Nordenberg, D., Williamson, D. F., Spitz, A. M., Edwards, V., Koss, M. P., \& Marks, J. S. (1998). Relationship of childhood abuse and household dysfunction to many of the leading causes of death in adults. The Adverse Childhood Experiences (ACE) Study. American Journal of Preventive Medicine, 14, 245-258. https://doi.org/10.1016/S0749-3797(98)00017-8

Finley, G. E., \& Schwartz, S. J. (2004). The father involvement and nurturant fathering scales: Retrospective measures for adolescent and adult children. Educational and Psychological Measurement, 64(1), 143-164.

Fuchs, A., Möhler, E., Resch, F., \& Kaess, M. (2015). Impact of a maternal history of childhood abuse on the development of mother-infant interaction during the first year of life. Child Abuse \& Neglect, 48, 179-189. https://doi.org/10.1016/j .chiabu.2015.05.023

Gladstone, T. R. G., Beardslee, W. R., \& Diehl, A. (2015). The impact of parental depression on children. In A. E. Reupert, D. Maybery, J. Nicholson, M. Gopfert, \& M. V. Seeman (Eds.), Parental psychiatric disorder: Distressed parents and their families (3rd ed.) (pp. 117-126). Cambridge University Press.

Goodman, S. H., Lusby, C. M., Thompson, K., Newport, D. J., \& Stowe, Z. N. (2014). Maternal depression in association with fathers' involvement with their infants: Spillover or compensation/buffering? Infant Mental Health Journal, 35(5), 495-508. https://doi.org/10.1002/imhj.21469

Guzzo, K. B. (2011). New father's experiences with their own fathers and attitudes toward fathering. Fathering, 9, 268-290. https://doi.org/10.3149/fth .0903 .268

Herbell, K., Li, Y., Bloom, T., Sharps, P., \& Bullock, L. F. C. (2020). Keeping it together for the kids: New mothers' descriptions of the impact of intimate partner violence on parenting. Child Abuse \& Neglect, 99, 104268. https://doi.org/10.1016/j .chiabu.2019.104268

Hicks, R., \& Tingley, D. (2011). Causal mediation analysis. The Stata Journal, 11(4), 605-619. https://doi.org/10.1177/1536867X1201100407

Hofferth, S. L., \& Goldscheider, F. (2010). Does change in young men's employment influence 
fathering? Family Relations, 59(4), 479-493. https://doi.org/10.1111/j.1741-3729.2010.00617 .x

Holmes, E. K., Baumgartner, J., Marks, L., Palkovitz, R., \& Nesteruk, O. (2010). Contemporary contradictions and challenges facing married fathers and mothers. In K. S. Pearlman (Ed.), Marriage: Roles, stability, and conflict (pp. 157-171). Nova Science Publishers.

Huber, S., \& Huber, O. W. (2012). The centrality of religiosity scale (CRS). Religions, 3, 710-724. https://doi.org/10.3390/rel3030710

Hummel, A. C., Kiel, E. J., \& Zvirblyte, S. (2016). Bidirectional effects of positive affect, warmth, and interactions between mothers with and without symptoms of depression and their toddlers. Journal of Child and Family Studies, 25(3), 781-789. https://doi.org/10.1007/s10826-015-0272-x

Jones, M. S., Sharp, S. F., \& Worthen, M. G. F. (2018). Broken hearts and battered lives: Adverse and abusive life histories and externalized responses to anger as pathways to illicit drug use among incarcerated women. Women \& Criminal Justice, 28(3), 167-188. https://doi.org/10.1080/08974454 .2017 .1372329

Khan, M., \& Renk, K. (2019). Mothers' adverse childhood experiences, depressive symptoms, parenting, and attachment as predictors of young children's problems. Journal of Child Custody, 16(3), 268-290. https://doi.org/10.1080/15379418 .2019.1575318

Kolomeyer, E., Renk, K., Cunningham, A., Lowell, A., \& Khan, M. (2016). Mothers' adverse childhood experiences and negative parenting behaviors: Connecting Mothers' difficult pasts to present parenting behavior via reflective functioning. Zero to three, 37(1), 5-12.

Kwon, H.-K., Rueter, M. A., Lee, M.-S., Koh, S., \& Ok, S. W. (2003). Marital relationships following the Korean economic crisis: Applying the family stress model. Journal of Marriage and Family, 65(2), 316-325. https://doi.org/10.1111/j $.1741-3737.2003 .00316 . x$

Lamb, M. E. (2010). How do fathers influence children's development? Let me count the ways. In M. E. Lamb (Ed.), The role of the father in child development (5th ed., pp. 1-26). Wiley.

Leach, L. S., Olesen, S. C., Butterworth, P., \& Poyser, C. (2014). New fatherhood and psychological distress: A longitudinal study of Australian men. American Journal of Epidemiology, 180(6), 582-589. https://doi.org/10.1093/aje/kwu177

Lee, S. J., Altschul, I., \& Gershoff, L. (2015). Wait until your father gets home? Fathers' and mothers' spanking and development of child aggression. Children and Youth Services Review, 52, $158-166$.

Lehman, B. J., Taylor, S. E., Kiefe, C. I., \& Seeman, T. E. (2009). Relationship of early life stress and psychological functioning to blood pressure in the CARDIA study. Health Psychology, 28(3), 338-346. https://doi.org/10.1037/a0013785

Liu, L., \& Wang, M. (2015). Parenting stress and harsh discipline in China: The moderating roles of marital satisfaction and parent gender. Child Abuse \& Neglect, 43, 73-82. https://doi.org/10 .1016/j.chiabu.2015.01.014

Living Wage Calculator. (2020). https://livingwage .mit.edu/

Lo, S., \& Andrews, S. (2015). To transform or not to transform: Using generalized linear mixed models to analyse reaction time data. Frontiers in Psychology, 6, 1171. https://doi.org/10.3389/fpsyg.2015 .01171

Magovcevic, M., \& Addis, M. E. (2008). The masculine depression scale: Development and psychometric evaluation. Psychology of Men \& Masculinity, 9(3), 117-132.

Mahalik, J. R., Locke, B. D., Ludlow, L. H., Diemer, M. A., Scott, R. P. J., Gottfried, M., \& Freitas, G. (2003). Development of the conformity to masculine norms inventory. Psychology of Men \& Masculinity, 4(1), 3-25. https://doi.org/10.1037/15249220.4.1.3

Martin, L. A., Neighbors, H. W., \& Griffith, D. M. (2013). The experience of symptoms of depression in men vs women: Analysis of the national comorbidity survey replication. JAMA Psychiatry, 70, 1100-1106. https://doi.org/10.1001/ jamapsychiatry.2013.1985

Nomaguchi, K., \& Milkie, M. A. (2017). Sociological perspectives on parenting stress: How social structure and culture shape parental strain and the well-being of parents and children. In K. Deater-Deckard \& R. Panneton (Eds.), Parental stress and early child development: Adaptive and maladaptive outcomes (pp. 47-73). Springer. https://doi.org/10.1007/978-3-319-55376-4_3

Nurius, P. S., Green, S., Logan-Greene, P., \& Borja, S. (2015). Life course pathways of adverse childhood experiences toward adult psychological well-being: A stress process analysis. Child Abuse \& Neglect, 45, 143-153. https://doi.org/10.1016/j .chiabu.2015.03.008

O’Neil, J., \& Luján, M. (2010). An assessment paradigm for fathers and men in therapy using gender role conflict theory. In C. Z. Oren \& D. C. Oren (Eds.), Counseling fathers (pp. 49-71). Routledge.

Padilla-Walker, L. M., Nielson, M. G., \& Day, R. D. (2016). The role of parental warmth and hostility on adolescents' prosocial behavior toward multiple targets. Journal of Family Psychology, 30, 331-340.

Palkovitz, R. (2019). Expanding our focus from father involvement to father-child relationship quality. Journal of Family Theory \& Review, 11(4), 576-591. https://doi.org/10.1111/jftr.12352 
Palkovitz, R., Trask, B. S., \& Adamsons, K. (2014). Essential differences in the meaning and processes of mothering and fathering: Family systems, feminist and qualitative perspectives. Journal of Family Theory \& Review, 6, 406-420.

Palkovitz, R., \& Hull, J. (2018). Toward a resource theory of fathering. Journal of Family Theory \& Review, 10(1), 181-198. https://doi.org/10.1111/ jftr.12239

Petts, R. J., Shafer, K., \& Essig, L. (2018). Does adherence to masculine norms shape fathering behavior? Journal of Marriage and Family, 80(3), 704-720. https://doi.org/10.1111/jomf.12476

Pew Research Center. (2016). Internet/broadband fact sheet. http://www.pewinternet.org

Pleck, J. H. (1995). The gender role strain paradigm: An update. In R. F. Levant \& W. S. Pollack (Ed.), A new psychology of men (pp. 1-32). Basic.

Pleck, J. H. (2010). Paternal involvement: Revised conceptualization and theoretical linkages with child outcomes. In M. E. Lamb (Ed.), The role of the father involvement in child development ( $\mathrm{pp}$. 58-93). Wiley \& Sons.

Ponnet, K. (2014). Financial stress, parent functioning and adolescent problem behavior: An actor-partner interdependence approach to family stress processes in low-, middle-, and high-income families. Journal of Youth and Adolescence, 43(10), 1752-1769. https://doi.org/10.1007/ s10964-014-0159-y

Preacher, K. J., \& Hayes, A. F. (2008). Asymptotic and resampling strategies for assessing and comparing indirect effects in multiple mediator models. Behavior Research Methods, 40(3), 879-891. https://doi.org/10.3758/BRM.40.3.879

Rosenfield, S., \& Mouzon, D. (2013). Gender and mental health. In C. S. Aneshensel, J. C. Phelan, \& A. Bierman (Eds.), Handbook of the sociology of mental health (pp. 277-296). Springer. https:// doi.org/10.1007/978-94-007-4276-5_14

Roy, K. (2014). Fathering from the long view: Framing personal and social change through life course theory. Journal of Family Theory \& Review, 6(4), 319-335. https://doi.org/10.1111/jftr.12050

Roy, K., \& Smith, J. (2012). Nonresident fathers and intergenerational parenting in kin networks. In N. Cabrera \& C. Tamis-LeMonda (Eds.), Handbook of Father Involvement: Multidisciplinary Perspectives, 2nd ed., pp. 320-337. New York, NY: Routledge.

Roy, K. M. (2006). Father stories: A life course examination of paternal identity among low-income African American men. Journal of Family Issues, 27(1), 31-54. https://doi.org/10.1177/ $0192513 \times 05275432$
Roy, K. M., Buckmiller, N., \& McDowell, A. (2008). Together but not "together": Trajectories of relationship suspension for low-income unmarried parents. Family Relations, 57(2), 198-210. https://doi .org/10.1111/j.1741-3729.2008.00494.x

Salari, R., Wells, M. B., \& Sarkadi, A. (2014). Child behaviour problems, parenting behaviours and parental adjustment in mothers and fathers in Sweden. Scandinavian Journal of Public Health, 42(7), 547-553. https://doi.org/10.1177/ 1403494814541595

Scheibling, C. (2018). "Real heroes care": How dad bloggers are reconstructing fatherhood and masculinities. Men and Masculinities, 23(1), 3-19. https://doi.org/10.1177/1097184X18816506

Schnarrs, P. W. (2019). Differences in adverse childhood experiences (ACEs) and quality of physical and mental health between transgender and cisgender sexual minorities. Journal of Psychiatric Research, 6, 1-6.

Schoppe-Sullivan, S. J., \& Fagan, J. (2020). The evolution of fathering research in the 21st century: Persistent challenges, new directions. Journal of Marriage and Family, 82(1), 175-197. https://doi .org/10.1111/jomf.12645

Schuetze, P., \& Eiden, R. D. (2005). The relationship between sexual abuse during childhood and parenting outcomes: Modeling direct and indirect pathways. Child Abuse \& Neglect, 29(6), 645-659. https://doi.org/10.1016/j.chiabu.2004.11.004

Shafer, K., Fielding, B., \& Holmes, E. K. (2019). Depression, masculine norm adherence, and fathering behavior. Journal of Family Issues, 40(1), 48-84.

Shafer, K., Fielding, B., \& Wendt, D. (2017). Similarities and differences in the influence of paternal and maternal depression on adolescent well-being. Social Work Research, 41, 85-96.

Shafer, K., Petts, R. J., \& Scheibling, C. (2020). Variation in masculinities and fathering behaviors: A cross-national comparison of the United States and Canada. Sex Roles. Online ahead of print. https://doi.org/10.1007/s11199-020-01177-3

Shafer, K., \& Renick, A. J. (2020). Depressive symptoms and father involvement in Canada: Evidence from a National Study. Canadian Review of Sociology/Revue Canadienne de Sociologie, 57(2), 197-222. https://doi.org/10.1111/cars.12277

Shears, J., Summers, J. A., Boller, K., \& Barclay-McLaughlin, G. (2006). Exploring fathering roles in low-income families: The influence of intergenerational transmission. Families in Society: The Journal of Contemporary Social Services, 87(2), 259-268. https://doi.org/10.1606/ 1044-3894.3519

Shin, S. H., \& Miller, D. P. (2012). A longitudinal examination of childhood maltreatment and adolescent obesity: Results from the National Longitudinal Study of Adolescent Health (AddHealth) 
Study. Child Abuse \& Neglect, 36(2), 84-94. https://doi.org/10.1016/j.chiabu.2011.08.007

Shin, S. H., Miller, D. P., \& Teicher, M. H. (2013). Exposure to childhood neglect and physical abuse and developmental trajectories of heavy episodic drinking from early adolescence into young adulthood. Drug and Alcohol Dependence, 127(1), 31-38. https://doi.org/10.1016/j.drugalcdep.2012 .06 .005

Silva, J. M. C. S., \& Tenreyro, S. (2006). The log of gravity. The Review of Economics and Statistics, 88(4), 641-658. https://doi.org/10.1162/rest.88.4 .641

Smith, S. M., Roster, C. A., Golden, L. L., \& Albaum, G. S. (2016). A multi-group analysis of online survey respondent data quality: Comparing a regular USA consumer panel to MTurk samples. Journal of Business Research, 69(8), 3139-3148. https:// doi.org/10.1016/j.jbusres.2015.12.002

Terhanian, G., Bremer, J., Olmsted, J., \& Guo, J. (2016). A process for developing an optimal model for reducing bias in nonprobability samples. Journal of Advertising Research, 56(1), 14-24.

Thomas, C. R., \& Holmes, E. K. (2019). Are father depression and masculinity associated with father perceptions of maternal gatekeeping? Journal of Family Psychology, 34, 490-495. https://doi.org/ 10.1037/fam0000604

Thornberry, T. P., Knight, K. E., \& Lovegrove, P. J. (2012). Does maltreatment beget maltreatment? A systematic review of the intergenerational literature. Trauma, Violence \& Abuse, 13(3), 135-152. https://doi.org/10.1177/1524838012447697

Tourangeau, R., Conrad, F. G., \& Couper, M. P. (2013). The science of web surveys. Oxford University Press.

Turney, K., \& Hardie, J. H. (2018). Health limitations among mothers and fathers: Implications for parenting. Journal of Marriage and Family, 80(1), 219-238. https://doi.org/10.1111/jomf .12425

Uchino, B. N., Bowen, K., Kent de Grey, R., Mikel, J., \& Fisher, E. B. (2018). Social support and physical health: Models, mechanisms, and opportunities. In E. B. Fisher, L. D. Cameron, A. J. Christensen, U. Ehlert, Y. Guo, B. Oldenburg, \& F. J. Snoek (Eds.), Principles and concepts of behavioral medicine: A global handbook (pp. 341-372). Springer. https://doi.org/10.1007/9780-387-93826-4_12

Umberson, D., Liu, H., \& Reczek, C. (2008). Stress and health behaviour over the life course. Advances in Life Course Research, 13, 19-44. https://doi.org/ 10.1016/S1040-2608(08)00002-6
Umberson, D., \& Williams, C. L. (1993). Divorced fathers: Parental role strain and psychological distress. Journal of Family Issues, 14, 378-400.

Umberson, D., Williams, K., Thomas, P. A., Liu, H., \& Thomeer, M. B. (2014). Race, gender, and chains of disadvantage: Childhood adversity, social relationships, and health. Journal of Health and Social Behavior, 55(1), 20-38. https://doi.org/10.1177/ 0022146514521426

Volling, B. L., \& Cabrera, N. J. (2019). Advancing research and measurement on fathering and child development: Introducing the issues and a conceptual framework. Soc Res Child Dev, 84, 7-17.

Weinberg, J. D., Freese, J., \& McElhattan, D. (2014). Comparing data characteristics and results of an online factorial survey between a population-based and a crowdsource-recruited sample. Sociological Science, 1, 292-310.

Widom, C. S., Czaja, S. J., \& DuMont, K. A. (2015). Intergenerational transmission of child abuse and neglect: Real or detection bias? Science (New York, N.Y.), 347(6229), 1480-1485. https://doi.org/ $10.1126 /$ science. 1259917

Williams, D. R. (2018). Stress and the mental health of populations of color: Advancing our understanding of race-related stressors. Journal of Health and Social Behavior, 59(4), 466-485.

Williams, K., \& Finch, B. K. (2019). Adverse childhood experiences, early and nonmarital fertility, and women's health at midlife. Journal of Health and Social Behavior, 60(3), 309-325. https://doi .org/10.1177/0022146519868842

Wilson, S., \& Durbin, C. E. (2010). Effects of paternal depression on fathers' parenting behaviors: A meta-analytic review. Clinical Psychology Review, 30, 167-180.

Yan, N., \& Ansari, A. (2016). Child adjustment and parent functioning: Considering the role of child driven effects. Journal of Family Psychology: Journal of the Division of Family Psychology of the American Psychological Association (Division 43), 30(3), 297-308. https://doi.org/10.1037/ fam0000180

Yang, K., \& Banamah, A. (2014). Quota sampling as an alternative to probability sampling? An experimental study. Sociological Research Online, 19(1), 1-11. https://doi.org/10.5153/sro.3199

Young, M., Schieman, S., \& Milkie, M. A. (2014). Spouse's work-to-family conflict, family stressors, and mental health among dual-earner mothers and fathers. Society and Mental Health, 4(1), 1-20. https://doi.org/10.1177/2156869313504931 